Bull. Austral. Math. Soc.

VoL. 57 (1998) [433-445]

\title{
ITERATION PROCESSES FOR APPROXIMATING FIXED POINTS OF OPERATORS OF MONOTONE TYPE
}

\author{
Shih-Sen Chang And KoK-Keong Tan
}

\begin{abstract}
In this paper, the unique fixed points of multi-valued and single-valued operators of monotone type are approximated by Ishikawa iteration processes or Mann and Ishikawa iteration processes with errors in uniformly smooth Banach spaces. The operators may not satisfy the Lipschitzian conditions and the domain or the range of the operators may not be bounded. The results presented improve and extend some recent results.
\end{abstract}

\section{Introduction and Preliminaries}

Throughout this paper, $X$ denotes a real Banach space, $X^{*}$ the dual space of $X$ and $\langle\cdot, \cdot\rangle$ the pairing between $X$ and $X^{*}$. If $D$ is any set, $2^{D}$ denotes the family of all non-empty subsets of $D$. The mapping $J: X \rightarrow 2^{X^{*}}$ denotes the normalised duality mapping defined by

$$
J(x)=\left\{f \in X^{*}:\langle x, f\rangle=\|f\| \cdot\|x\|,\|f\|=\|x\|\right\} .
$$

The following proposition gives some basic properties of normalised duality mappings.

Proposition 1.1. The normalised duality mapping $J: X \rightarrow 2^{X^{*}}$ has the following properties:

1. $J(x) \neq \emptyset$ for all $x \in X$ and $D(J)$ (the domain of $J)=X$;

2. $J(\alpha x)=\alpha \cdot J(x)$ for all $\alpha \in[0, \infty)$;

3. $J(-x)=-J(x)$;

4. $J$ is bounded, that is, for any bounded subset $A \subset X, J(A)$ is a bounded subset in $X^{*}$;

5. (Smul'yan $[9,10])$.$X is uniformly smooth if and only if J$ is single-valued and uniformly continuous on any bounded subset of $X$.

Received 18th September, 1997

Copyright Clearance Centre, Inc. Serial-fee code: 0004-9729/98 $\$$ A2.00+0.00. 
DEFinition 1.1: Let $D$ be a nonempty subset of $X$ and $T: D \rightarrow 2^{X}$ be a multi-valued operator.

(1) $T$ is said to be of monotone type if there exist a constant $k \in(0,1)$ and an $x^{*} \in D$ such that for each $x \in D$ there exists $j\left(x-x^{*}\right) \in J\left(x-x^{*}\right)$ satisfying

$$
\left\langle\xi-x^{*}, j\left(x-x^{*}\right)\right\rangle \leqslant k \cdot\left\|x-x^{*}\right\|^{2} \quad \text { for all } \quad \xi \in T x .
$$

(2) $T$ is strongly (or strictly) accretive if there is a constant $k \in(0,1)$, called the strong accretive constant for $T$, such that for each $x, y \in D$, for each $u \in T(x), v \in T(y)$, there exists $j \in J(x-y)$ with $\langle u-v, j\rangle \geqslant k\|x-y\|^{2}$.

(3) $T$ is strongly (or strictly) pseudo-contractive if $I-T$ is strongly accretive, where $I$ is the identity operator on $D$.

The following is a special case of $[1$, Lemma 3.1]. For completeness, we shall include its proof here (which was omitted in [1]).

Lemma 1.1. Let $D$ be a non-empty subset of $X$. If $T: D \rightarrow 2^{X}$ is strongly pseudo-contractive, then for each $x, y \in X$, each $u \in T(x)$ and $v \in T(y)$, there exists $j \in J(x-y)$ such that

$$
\langle u-v, j\rangle \leqslant(1-k)\|x-y\|^{2}
$$

where $k \in(0,1)$ is the strong accretive constant of $I-T$.

Proof: Since $T$ is strongly pseudo-contractive, there is a constant $k \in(0,1)$ such that for each $x, y \in D$, for each $u^{\prime} \in(I-T)(x), v^{\prime} \in(I-T)(y)$, there exists $j \in J(x-y)$ with $\left\langle u^{\prime}-v^{\prime}, j\right\rangle \geqslant k\|x-y\|^{2}$. Let $u \in T(x), v \in T(y)$ be such that $u^{\prime}=x-u, v^{\prime}=y-v$. It follows that

$$
\langle x-u-(y-v), j\rangle \geqslant k \dot{\| x}-y \|^{2}
$$

that is,

$$
\langle x-y, j\rangle-\langle u-v, j\rangle \geqslant k \dot{\| x}-y \|^{2} \text {. }
$$

Hence

$$
\|x-y\|^{2}-k\|x-y\|^{2} \geqslant\langle u-v, j\rangle \text {, }
$$

that is,

$$
\langle u-v, j\rangle \leqslant(1-k)\|x-y\|^{2} \text {. }
$$

REMARK. From Lemma 1.1 , it is easy to see that a strongly (strictly) pseudocontractive mapping with a fixed point is of monotone type. For results on strongly accretive mappings or strongly pseudo-contractive mappings, we refer to Chidume [3, 4], Deng and Ding [5], Osilike [8], Tan and $X u$ [11]) and the references therein.

In [6], Dunn showed that if $X$ is a Hilbert space, $T: D \rightarrow 2^{X}$ is an operator of monotone type and $y \in D$ is a fixed point of $T$, then $y=x^{*}$, so that $T$ can have at 
most one fixed point. Moreover, if the range of $T$ is bounded, that is, there exists some $\delta>0$ such that

$$
\|\xi-\eta\| \leqslant \delta
$$

for all $x, y \in D, \xi \in T x, \eta \in T y$ and if further $\left\{x_{n}\right\}_{n=0}^{\infty}$ is a sequence in $D$ satisfying

$$
x_{n+1}=\left(1-c_{n}\right) x_{n}+c_{n} \xi_{n}, \quad \text { where } \quad \xi_{n} \in T x_{n} \text { for each } n \geqslant 0 \text {, }
$$

and $\left\{c_{n}\right\}_{n=0}^{\infty} \subset(0,1]$ satisfies

$$
\sum_{n=0}^{\infty} c_{n}^{2}<\infty \quad \text { and } \quad \sum_{n=0}^{\infty} c_{n}=\infty
$$

then $\left\{x_{n}\right\}$ converges strongly to $x^{*}$.

In [2], Chidume generalised Dunn's above result to $L_{p}$ spaces for $p \geqslant 2$.

The purpose in this paper is to study the approximate problems of fixed points for single-valued and multi-valued operators of monotone type by Ishikawa iteration processes or Mann and Ishikawa iteration processes with errors in uniformly smooth Banach spaces. The operator may not satisfy Lipchitzian condition and the domain or range of the operator may not be bounded. Our results presented in this paper improve and extend some recent results of Chang [1], Chidume [2, 3, 4], Deng and Ding [5], Dunn [6] and Tan and $\mathrm{Xu}[\mathbf{1 1}]$.

For the sake of convenience, we first give some definitions and conclusions.

The Banach space $X$ is said to be uniformly smooth, if the modulus of smoothness $\rho_{X}(\cdot)$ of $X$, which is defined by

$$
\rho_{X}(\tau)=\frac{1}{2} \sup \{\|x+y\|+\|x-y\|-2: x, y \in X,\|x\|=1,\|y\| \leqslant \tau\}, \tau>0,
$$

satisfies the following condition:

$$
\lim _{\tau \rightarrow 0^{+}} \frac{1}{\tau} \rho_{X}(\tau)=0
$$

I The Mann iteration process. Let $D$ be a nonempty convex subset of $X$ and $T: D \rightarrow D$ a mapping. The sequence $\left\{x_{n}\right\} \subset D$ defined by

$$
x_{0} \in D, x_{n+1}=\left(1-\alpha_{n}\right) x_{n}+\alpha_{n} T x_{n}, n \geqslant 0 \text {, }
$$

where $\left\{\alpha_{n}\right\}$ is a sequence in $(0,1]$ satisfying some additive conditions, is called a Mann iteration process. 
II The IshiKaWA ITERATION PROCESS. Let $D$ be a nonempty convex subset of $X$ and $T: D \rightarrow D$ a mapping. The sequence $\left\{x_{n}\right\} \subset D$ defined by

$$
\left\{\begin{aligned}
x_{0} \in D, x_{n+1} & =\left(1-\alpha_{n}\right) x_{n}+\alpha_{n} T y_{n}, \\
y_{n} & =\left(1-\beta_{n}\right) x_{n}+\beta_{n} T x_{n},
\end{aligned}\right.
$$

where $\left\{\alpha_{n}\right\}$ and $\left\{\beta_{n}\right\}$ are two sequences in $[0,1]$ satisfying some additive conditions is called an Ishikawa iteration process.

The above two iteration processes have been extensively studied by many authors for approximating either fixed points of nonlinear mappings or solutions of nonlinear operator equations in Banach spaces.

Recently, in [7], Liu introduced and studied the following Ishikawa iteration process with errors:

III The IshikaWA ITERATION PROCESS WITH ERRORS. Let $D$ be a nonempty subset of $X$ and $T: D \rightarrow D$ a mapping. The sequence $\left\{x_{n}\right\} \subset D$ defined by

$$
\left\{\begin{aligned}
x_{0} \in D, x_{n+1} & =\left(1-\alpha_{n}\right) x_{n}+\alpha_{n} T y_{n}+u_{n}, \\
y_{n} & =\left(1-\beta_{n}\right) x_{n}+\beta_{n} T x_{n}+v_{n},
\end{aligned}\right.
$$

where $\left\{u_{n}\right\}$ and $\left\{v_{n}\right\}$ are two sequences in $X$ and $\left\{\alpha_{n}\right\},\left\{\beta_{n}\right\}$ are two real sequences in $[0,1]$ satisfying some additive conditions, is called an Ishikawa iteration process with errors. In particular, if $\beta_{n}=0, v_{n}=0$ for all $n \geqslant 0$, then the sequence $\left\{x_{n}\right\}$ is called a Mann iteration process with errors.

It is obvious that, the Mann and Ishikawa iteration processes both are special cases of the Ishikawa iteration process with errors.

The following result is [1, Lemma 2.1$]$ :

Lemma 1.2. For any $x, y \in X$, we have

$$
\|x+y\|^{2} \leqslant\|x\|^{2}+2\langle y, j\rangle \quad \text { for all } \quad j \in J(x+y) .
$$

The following result is [7, Lemma 2]:

LEMmA 1.3. Let $\left\{a_{n}\right\}_{n=0}^{\infty},\left\{b_{n}\right\}_{n=0}^{\infty}$ and $\left\{c_{n}\right\}_{n=0}^{\infty}$ be three nonnegative real sequences satisfying the following condition:

$$
a_{n+1} \leqslant\left(1-t_{n}\right) a_{n}+b_{n}+c_{n} \text { for all } n \geqslant n_{0},
$$

where $n_{0}$ is some positive integer, $\left\{t_{n}\right\}_{n=0}^{\infty}$ is a sequence in $[0,1], \sum_{n=0}^{\infty} t_{n}=\infty, b_{n}=$ $o\left(t_{n}\right)$ and $\sum_{n=0}^{\infty} c_{n}<\infty$.

Then $\lim _{n \rightarrow \infty} a_{n}=0$. 


\section{Ishikawa Iteration Process of Fixed Points for Single-valued OPERATORS OF MONOTONE TYPE}

THEOREM 2.1. Suppose that $X$ is uniformly smooth, $K$ is a nonempty closed convex subset of $X$ and $T: K \rightarrow K$ is a single-valued operator of monotone type (the range $T(K)$ of $T$ need not be bounded). If the set $F i x(T)$ of fixed points of $T$ is non-empty, then

(1) for any $q \in F i x(T)$, we have $q=x^{*}$, where $x^{*}$ is the point appearing in (1.1), and so $T$ has a unique fixed point in $K$.

(2) Suppose, in addition, if $T$ is a Lipschitzian mapping with Lipschitzian constant $L \geqslant 1$, and $\left\{\alpha_{n}\right\},\left\{\beta_{n}\right\}$ are two sequences in $[0,1]$ satisfying the following conditions:

(i) $0 \leqslant \beta_{n} \leqslant(1-k)^{2} /(L(1+L))$, where $k$ is the constant appearing in (1.1),

(ii) $\sum_{n=0}^{\infty} \alpha_{n}=\infty$ and $\alpha_{n} \rightarrow 0$ as $n \rightarrow \infty$.

Then for any $x_{0} \in K$, the Ishikawa iteration sequence $\left\{x_{n}\right\}$ defined by

$$
\left\{\begin{array}{rl}
x_{n+1} & =\left(1-\alpha_{n}\right) x_{n}+\alpha_{n} T y_{n} \\
y_{n} & =\left(1-\beta_{n}\right) x_{n}+\beta_{n} T x_{n}
\end{array} \quad n \geqslant 0\right.
$$

converges strongly to the unique fixed point of $T$ in $K$.

Proof: (1) For any $q \in F i x(T)$, we have $q=T q$. Since $X$ is uniformly smooth, the normalised duality mapping $J$ is sinlge-valued. Because $T$ is a singlevalued operator of monotone type, from (1.1) we have

$$
\left\langle q-x^{*}, J\left(q-x^{*}\right)\right\rangle \leqslant k\left\|q-x^{*}\right\|^{2},
$$

and so

$$
\left\|q-x^{*}\right\|^{2} \leqslant k\left\|q-x^{*}\right\|^{2} .
$$

Since $k \in(0,1)$, we have $\left\|q-x^{*}\right\|=0$, that is, $q=x^{*}$.

(2) Let $q \in K$ be the unique fixed point of $T$. If there exists a positive integer $n_{o}$ such that $x_{n_{0}}=q$, then we have

$$
y_{n_{0}}=\left(1-\beta_{n_{0}}\right) q+\beta_{n_{0}} T q=q,
$$

and so

$$
x_{n_{0}+1}=\left(1-\alpha_{n_{0}}\right) q+\alpha_{n_{0}} q=q .
$$

By induction, we can prove that $x_{n_{0}+i}=q$ for all $i \geqslant 1$. This implies that $x_{n} \rightarrow q$ and the conclusion of Theorem 2.1 is proved. Consequently, without loss of generality, we may assume that $x_{n} \neq q$ for all $n \geqslant 0$, that is, $\left\|x_{n}-q\right\|>0$ for all $n \geqslant 0$. 
Since $X$ is uniformly smooth, $J$ is single-valued and is uniformly continuous on every bounded subset of $X$. From Lemma 1.1 we have

$$
\begin{aligned}
\left\|x_{n+1}-q\right\|^{2}= & \left\|\left(1-\alpha_{n}\right)\left(x_{n}-q\right)+\alpha_{n}\left(T y_{n}-q\right)\right\|^{2} \\
\leqslant & \left(1-\alpha_{n}\right)^{2}\left\|x_{n}-q\right\|^{2}+2 \alpha_{n}\left\langle T y_{n}-q, J\left(x_{n+1}-q\right)\right\rangle \\
= & (1-\alpha)^{2}\left\|x_{n}-q\right\|^{2}+2 \alpha_{n}\left\langle T y_{n}-q, J\left(x_{n}-q\right)\right\rangle \\
& \quad+2 \alpha_{n}\left\langle T y_{n}-q, J\left(x_{n+1}-q\right)-J\left(x_{n}-q\right)\right\rangle \\
= & \left(1-\alpha_{n}\right)^{2}\left\|x_{n}-q\right\|^{2}+2 \alpha_{n}\left\langle T y_{n}-q, J\left(x_{n}-q\right)\right\rangle \\
& \quad+2 \alpha_{n} \gamma_{n} \cdot\left\|x_{n}-q\right\|^{2},
\end{aligned}
$$

where

$$
\gamma_{n}=\left\langle\frac{T y_{n}-q}{\left\|x_{n}-q\right\|}, J\left(\frac{x_{n+1}-q}{\left\|x_{n}-q\right\|}\right)-J\left(\frac{x_{n}-q}{\left\|x_{n}-q\right\|}\right)\right\rangle
$$

(I) First we consider the second term on the right side of (2.2).

Since $T$ is a single-valued operator of monotone type, we have

$$
\left\langle T x_{n}-q, J\left(x_{n}-q\right)\right\rangle \leqslant k\left\|x_{n}-q\right\|^{2} .
$$

Again since $T$ is a Lipschitzian mapping, we have

$$
\begin{aligned}
\left\|T y_{n}-T x_{n}\right\| & \leqslant L \cdot\left\|y_{n}-x_{n}\right\| \leqslant L \cdot \beta_{n} \cdot\left\|x_{n}-T x_{n}\right\| \\
& \leqslant L \cdot \beta_{n} \cdot\left\{\left\|T x_{n}-q\right\|+\left\|x_{n}-q\right\|\right\} \\
& \leqslant L \cdot \beta_{n} \cdot(1+L) \cdot\left\|x_{n}-q\right\| \\
& \leqslant(1-k)^{2}\left\|x_{n}-q\right\| \quad \text { (by condition (i)). }
\end{aligned}
$$

It follows from (2.3) and (2.4) that

$$
\begin{aligned}
\left\langle T y_{n}-T q, J\left(x_{n}-q\right)\right\rangle & =\left\langle T y_{n}-T x_{n}, J\left(x_{n}-q\right)\right\rangle+\left\langle T x_{n}-q, J\left(x_{n}-q\right)\right\rangle \\
& \leqslant(1-k)^{2} \cdot\left\|x_{n}-q\right\|^{2}+k\left\|x_{n}-q\right\|^{2} \\
& =\left(1-k+k^{2}\right) \cdot\left\|x_{n}-q\right\|^{2}
\end{aligned}
$$

(II) Next we consider the third term on the right side of (2.2). We shall show that $\gamma_{n} \rightarrow 0$ as $n \rightarrow \infty$. Indeed, since

$$
\begin{aligned}
\left\|y_{n}-q\right\| & \leqslant\left(1-\beta_{n}\right)\left\|x_{n}-q\right\|+\beta_{n}\left\|T x_{n}-T q\right\| \\
& \leqslant\left(1-\beta_{n}\right)\left\|x_{n}-q\right\|+\beta_{n} \cdot L\left\|x_{n}-q\right\| \\
& \leqslant L \cdot\left\|x_{n}-q\right\|
\end{aligned}
$$


it follows that

$$
\frac{\left\|T y_{n}-q\right\|}{\left\|x_{n}-q\right\|} \leqslant L \cdot \frac{\left\|y_{n}-q\right\|}{\left\|x_{n}-q\right\|} \leqslant L^{2} .
$$

By the assumption that $\alpha_{n} \rightarrow 0$ as $n \rightarrow \infty$ and by (2.7), we have

$$
\begin{aligned}
\left\|\frac{x_{n+1}-q}{\left\|x_{n}-q\right\|}-\frac{x_{n}-q}{\left\|x_{n}-q\right\|}\right\| & =\frac{\alpha_{n}}{\left\|x_{n}-q\right\|}\left\|T y_{n}-x_{n}\right\| \\
& \leqslant \frac{\alpha_{n}}{\left\|x_{n}-q\right\|}\left\{\left\|T y_{n}-q\right\|+\left\|x_{n}-q\right\|\right\} \\
& \leqslant \alpha_{n}\left(L^{2}+1\right) \rightarrow 0 \text { as } n \rightarrow \infty .
\end{aligned}
$$

Moreover, since for each $n \geqslant 0$,

$$
\begin{aligned}
\left\|\frac{x_{n+1}-q}{\left\|x_{n}-q\right\|}\right\| & =\frac{\left\|\left(1-\alpha_{n}\right)\left(x_{n}-q\right)+\alpha_{n}\left(T y_{n}-q\right)\right\|}{\left\|x_{n}-q\right\|} \\
& \leqslant\left(1-\alpha_{n}\right)+\alpha_{n} \frac{\left\|T y_{n}-q\right\|}{\left\|x_{n}-q\right\|} \\
& \leqslant\left(1-\alpha_{n}\right)+\alpha_{n} L^{2} \quad \text { (by (2.7)) } \\
& \leqslant L^{2},
\end{aligned}
$$

the set $\left\{\left(x_{n+1}-q\right) /\left\|x_{n}-q\right\|,\left(x_{n}-q\right) /\left\|x_{n}-q\right\|\right\}_{n=0}^{\infty}$ is bounded. Since $J$ is uniformly continuous on any bounded subset of $X,(2.8)$ shows that

$$
J\left(\frac{x_{n+1}-q}{\left\|x_{n}-q\right\|}\right)-J\left(\frac{x_{n}-q}{\left\|x_{n}-q\right\|}\right) \rightarrow 0 \text { as } n \rightarrow \infty .
$$

It follows from (2.7) and (2.9) that $\gamma_{n} \rightarrow 0$ as $n \rightarrow \infty$.

Substituting (2.5) into (2.2) and simplifying we have

$$
\left\|x_{n+1}-q\right\|^{2} \leqslant\left[\left(1-\alpha_{n}\right)^{2}+2 \alpha_{n}\left(1-k+k^{2}\right)+2 \alpha_{n} \gamma_{n}\right]\left\|x_{n}-q\right\|^{2} .
$$

Since $\alpha_{n} \rightarrow 0$ as $n \rightarrow \infty, \gamma_{n} \rightarrow 0(n \rightarrow \infty)$ and

$$
\left(1-\alpha_{n}\right)^{2}+2 \alpha_{n}\left(1-k+k^{2}\right)+2 \alpha_{n} \gamma_{n}=1-\alpha_{n}\left(k-k^{2}\right)-\alpha_{n}\left(k-k^{2}-\alpha_{n}+2 \gamma_{n}\right),
$$

there exists a positive integer $n_{0}$ such that $k-k^{2}-\alpha_{n}+2 \gamma_{n}>0$ for all $n \geqslant n_{0}$. Therefore we have

$$
\left\|x_{n+1}-q\right\|^{2} \leqslant\left(1-\alpha_{n}\left(k-k^{2}\right)\right)\left\|x_{n}-q\right\|^{2} \text { for all } n \geqslant n_{0} .
$$

Apply Lemma 1.3 with $a_{n}=\left\|x_{n}-q\right\|^{2}, t_{n}=\left(k-k^{2}\right) \alpha_{n}, b_{n}=0$ and $c_{n}=0$, and we have

$$
\left\|x_{n}-q\right\|^{2} \rightarrow 0 \text { as } n \rightarrow \infty \text {; that is, } x_{n} \rightarrow q \text { as } n \rightarrow \infty
$$


REMARK. As we mentioned above, every strictly pseudo-contractive mapping with a fixed point in a Banach space is an operator of monotone type. Therefore Theorem 2.1 generalises the corresponding results of Chidume [2, Theorem 1]; [3, Theorem 2; 4, Theorem 4], Deng and Ding [5, Theorem 1], Tan and Xu [11, Theorem 3.2 and Theorem 4.2], Dunn [6, Theorem 1] and Chang [1, Theorem 3.3] in several aspects. It will be of interest to compare our Theorem 2.1 with [8, Theorem 1].

\section{Ishikawa Iteration Processes with Errors of Fixed Point for Multi-valued Operators of Monotone TyPe}

TheOREM 3.1. Suppose $X$ is uniformly smooth, $D$ is a nonempty subset of $X$, $T: D \rightarrow 2^{X}$ is a multi-valued operator of monotone type such that Fix $(T) \neq \emptyset$.

(1) If $q \in F i x(T)$, then $x^{*}=q$, where $x^{*}$ is the point appearing in (1.1), so that $T$ has a unique fixed point in $D$.

(2) Suppose that $T(D)$ is bounded in $X$, and that $\left\{u_{n}\right\}_{n=0}^{\infty},\left\{v_{n}\right\}_{n=0}^{\infty}$ are two sequences in $X$ and $\left\{\alpha_{n}\right\}_{n=0}^{\infty},\left\{\beta_{n}\right\}_{n=0}^{\infty}$ are two sequences in $[0,1]$ satisfying the following conditions

$$
\begin{aligned}
& \text { (i) } \sum_{n=0}^{\infty}\left\|u_{n}\right\|<\infty, \lim _{n \rightarrow \infty}\left\|v_{n}\right\|=0 \text {; } \\
& \text { (ii) } \sum_{n=0}^{\infty} \alpha_{n}=\infty, \alpha_{n} \rightarrow 0, \beta_{n} \rightarrow 0 \text { as } n \rightarrow \infty .
\end{aligned}
$$

If there exists some $x_{0} \in D$ such that the Ishikawa iteration process with errors $\left\{x_{n}\right\},\left\{y_{n}\right\} \subset D$ defined by

$$
\left\{\begin{array}{rl}
x_{n+1} & =\left(1-\alpha_{n}\right) x_{n}+\alpha_{n} \eta_{n}+u_{n}, \text { where } \eta_{n} \in T y_{n} \\
y_{n} & =\left(1-\beta_{n}\right) x_{n}+\beta_{n} \xi_{n}+v_{n}, \text { where } \xi_{n} \in T x_{n}
\end{array} \quad n \geqslant 0,\right.
$$

then $\left\{x_{n}\right\}$ converges strongly to the unique fixed point $x^{*}$.

Proof: (1) Let $q \in D$ be a fixed point of $T$. Since $T$ is of monotone type, from (1.1) we have

$$
\left\langle q-x^{*}, J\left(q-x^{*}\right)\right\rangle \leqslant k\left\|q-x^{*}\right\|^{2} .
$$

Therefore, we have

$$
(1-k)\left\|q-x^{*}\right\|^{2} \leqslant 0 .
$$

Since $k \in(0,1)$, we have $\left\|q-x^{*}\right\|^{2}=0$, that is, $q=x^{*}$. This implies that $T$ has at most one fixed point in $D$.

(2) Since $T(D)$ is bounded, let

$$
\begin{aligned}
d & =\sup \left\{\left\|\xi-x^{*}\right\|: \xi \in T x, x \in D\right\}+\left\|x_{0}-x^{*}\right\|, \\
M & =d+\sum_{n=0}^{\infty}\left\|u_{n}\right\|+1
\end{aligned}
$$


Now we shall prove that

$$
\left\|x_{n+1}-x^{*}\right\| \leqslant d+\sum_{i=0}^{n}\left\|u_{i}\right\| \leqslant M, \text { for each } n \geqslant 0 .
$$

Indeed, when $n=0$, we have

$$
\begin{aligned}
\left\|x_{1}-x^{*}\right\| & \leqslant\left\|\left(1-\alpha_{0}\right)\left(x_{0}-x^{*}\right)+\alpha_{0}\left(\eta_{0}-x^{*}\right)\right\|+\left\|u_{0}\right\| \\
& \leqslant\left\|x_{0}-x^{*}\right\|+\left\|\eta_{0}-x^{*}\right\|+\left\|u_{0}\right\| \\
& \leqslant d+\left\|u_{0}\right\| \leqslant M .
\end{aligned}
$$

Suppose (3.4) is true for $n=k \geqslant 1$, then

$$
\begin{aligned}
\left\|x_{k+1}-x^{*}\right\| & =\left\|\left(1-\alpha_{k}\right)\left(x_{k}-x^{*}\right)+\alpha_{k}\left(\eta_{k}-x^{*}\right)+u_{k}\right\| \\
& \leqslant\left(1-\alpha_{k}\right)\left\|x_{k}-x^{*}\right\|+\alpha_{k}\left\|\eta_{k}-x^{*}\right\|+\left\|u_{k}\right\| \\
& \leqslant\left(1-\alpha_{k}\right)\left(d+\sum_{i=0}^{k-1}\left\|u_{i}\right\|\right)+\alpha_{k}\left\|\eta_{k}-x^{*}\right\|+\left\|u_{k}\right\| \\
& \leqslant d+\sum_{i=0}^{k}\left\|u_{i}\right\| \leqslant M
\end{aligned}
$$

Thus (3.4) holds by induction.

By (3.2) and (3.4), we have

$$
\begin{aligned}
& \max \left\{\left\|\left(1-\alpha_{n}\right)\left(x_{n}-x^{*}\right)+\alpha_{n}\left(\eta_{n}-x^{*}\right)\right\|, 1\right\} \leqslant \max \{M, 1\}=M_{1} \\
& \max \left\{\left\|\left(1-\beta_{n}\right)\left(x_{n}-x^{*}\right)+\beta_{n}\left(\xi_{n}-x^{*}\right)\right\|, 1\right\} \leqslant \max \{M, 1\}=M_{1} .
\end{aligned}
$$

On the other hand, by (3.1) and Lemma 1.1, we have

$$
\begin{aligned}
\left\|x_{n+1}-x^{*}\right\|^{2}= & \left\|\left(1-\alpha_{n}\right)\left(x_{n}-x^{*}\right)+\alpha_{n}\left(\eta_{n}-x^{*}\right)+u_{n}\right\|^{2} \\
\leqslant & \left\|\left(1-\alpha_{n}\right)\left(x_{n}-x^{*}\right)+\alpha_{n}\left(\eta_{n}-x^{*}\right)\right\|^{2}+2\left\langle u_{n}, J\left(x_{n+1}-x^{*}\right)\right\rangle \\
\leqslant & \left(1-\alpha_{n}\right)^{2}\left\|x_{n}-x^{*}\right\|^{2}+2 \alpha_{n}\left\langle\eta_{n}-x^{*}, J\left(x_{n+1}-x^{*}-u_{n}\right)\right\rangle \\
& \quad+2\left\langle u_{n}, J\left(x_{n+1}-x^{*}\right)\right\rangle .
\end{aligned}
$$

(I) First we consider the third term on the right side of (3.7). We have

$$
\begin{aligned}
\left\langle u_{n}, J\left(x_{n+1}-x^{*}\right)\right\rangle & \leqslant\left\|u_{n}\right\| \cdot\left\|x_{n+1}-x^{*}\right\| \\
& \leqslant M \cdot\left\|u_{n}\right\| .
\end{aligned}
$$


(II) Next we consider the second term on the right side of (3.7). From (1.1), we have

$$
\begin{aligned}
\left\langle\eta_{n}-x^{*}, J\left(x_{n+1}-x^{*}-u_{n}\right)\right\rangle= & \left\langle\eta_{n}-x^{*}, J\left(y_{n}-x^{*}\right)\right\rangle \\
& +\left\langle\eta_{n}-x^{*}, J\left(x_{n+1}-x^{*}-u_{n}\right)-J\left(y_{n}-x^{*}\right)\right\rangle \\
\leqslant & k \cdot\left\|y_{n}-x^{*}\right\|^{2}+d_{n}
\end{aligned}
$$

where

$$
d_{n}=\left\langle\eta_{n}-x^{*}, J\left(x_{n+1}-x^{*}-u_{n}\right)-J\left(y_{n}-x^{*}\right)\right\rangle .
$$

Now we claim that

$$
d_{n} \rightarrow 0 \text { as } n \rightarrow \infty
$$

Indeed, from (3.1), (3.2), (3.4) and conditions (i) and (ii), we have

$$
\begin{aligned}
& \left\|\left(x_{n+1}-x^{*}-u_{n}\right)-\left(y_{n}-x^{*}\right)\right\|=\left\|x_{n+1}-y_{n}-u_{n}\right\| \\
& \quad=\left\|\beta_{n}\left(x_{n}-\xi_{n}\right)-\alpha_{n}\left(x_{n}-\eta_{n}\right)-u_{n}\right\| \\
& \quad \leqslant \beta_{n}\left[\left\|x_{n}-x^{*}\right\|+\left\|\xi_{n}-x^{*}\right\|\right]+\alpha_{n}\left[\left\|x_{n}-x^{*}\right\|+\left\|\eta_{n}-x^{*}\right\|\right]+\left\|u_{n}\right\| \\
& \quad \leqslant \beta_{n}(M+d)+\alpha_{n}(M+d)+\left\|u_{n}\right\| \rightarrow 0 \text { as } n \rightarrow \infty .
\end{aligned}
$$

Since $X$ is uniformly smooth, $J$ is uniformly continuous on any bounded subset of $X$. Hence we have

$$
\left\|J\left(x_{n+1}-x^{*}-u_{n}\right)-J\left(y_{n}-x^{*}\right)\right\| \rightarrow 0 \text { as } n \rightarrow \infty
$$

Consequently, we have

$$
\begin{aligned}
\left|d_{n}\right| & \leqslant\left\|\eta_{n}-x^{*}\right\| \cdot\left\|J\left(x_{n+1}-x^{*}-u_{n}\right)-J\left(y_{n}-x^{*}\right)\right\| \\
& \leqslant d \cdot\left\|J\left(x_{n+1}-x^{*}-u_{n}\right)-J\left(y_{n}-x^{*}\right)\right\| \rightarrow 0 \text { as } n \rightarrow \infty .
\end{aligned}
$$

Moreover, by (3.1) and Lemma 1.1, we have

$$
\begin{aligned}
\left\|y_{n}-x^{*}\right\|^{2}= & \left\|\left(1-\beta_{n}\right)\left(x_{n}-x^{*}\right)+\beta_{n}\left(\xi_{n}-x^{*}\right)+v_{n}\right\|^{2} \\
\leqslant & \left\|\left(1-\beta_{n}\right)\left(x_{n}-x^{*}\right)+\beta_{n}\left(\xi_{n}-x^{*}\right)\right\|^{2}+2\left\langle v_{n}, J\left(y_{n}-x^{*}\right)\right\rangle \\
\leqslant & \left(1-\beta_{n}\right)^{2}\left\|x_{n}-x^{*}\right\|^{2}+2 \beta_{n}\left\langle\xi_{n}-x^{*}, J\left(y_{n}-x^{*}-v_{n}\right)\right\rangle \\
& \quad+2\left\langle v_{n}, J\left(y_{n}-x^{*}\right)\right\rangle \\
\leqslant & \left(1-\beta_{n}\right)^{2}\left\|x_{n}-x^{*}\right\|^{2}+2 \beta_{n}\left\|\xi_{n}-x^{*}\right\| \cdot\left\|y_{n}-x^{*}-v_{n}\right\| \\
& \quad+2\left\|v_{n}\right\| \cdot\left\|y_{n}-x^{*}\right\| .
\end{aligned}
$$

By (3.2), (3.3) and (3.4), it follows from (3.11) that

$$
\left\|y_{n}-x^{*}\right\|^{2} \leqslant\left(1-\beta_{n}\right)^{2} M^{2}+2 \beta_{n} \cdot d \cdot\left\{\left\|y_{n}-x^{*}\right\|+\left\|v_{n}\right\|\right\}+2\left\|v_{n}\right\| \cdot\left\|y_{n}-x^{*}\right\|,
$$


which implies that $\left\{\left\|y_{n}-x^{*}\right\|\right\}_{n=0}^{\infty}$ is a bounded sequence as $\left\{\left\|v_{n}\right\|\right\}_{n=0}^{\infty}$ is also bounded by (i).

Let $M_{2}=\sup \left\{\left\|y_{n}-x^{*}\right\|\right\}$. Then $M_{2}<\infty$ and from (3.11) we have

$$
\left\|y_{n}-x^{*}\right\|^{2} \leqslant\left\|x_{n}-x^{*}\right\|^{2}+2 \beta_{n} \cdot d\left(M_{2}+\left\|v_{n}\right\|\right)+2\left\|v_{n}\right\| \cdot M_{2} .
$$

Substituting (3.12) into (3.9), we have

$$
\begin{aligned}
\left\langle\eta_{n}-x^{*}, J\left(x_{n+1}-x^{*}-u_{n}\right)\right\rangle \leqslant k\{ & \left\|x_{n}-x^{*}\right\|^{2}+2 \beta_{n} d\left(M_{2}+\left\|v_{n}\right\|\right) \\
& \left.+2\left\|v_{n}\right\| \cdot M_{2}\right\}+d_{n}=k\left\|x_{n}-x^{*}\right\|^{2}+e_{n}
\end{aligned}
$$

where

$$
e_{n}=k\left\{2 \beta_{n} d\left(M_{2}+\left\|v_{n}\right\|\right)+2\left\|v_{n}\right\| \cdot M_{2}\right\}+d_{n} \rightarrow 0 \text { as } n \rightarrow \infty
$$

by conditions (i) and (ii).

Substituting (3.8) and (3.13) into (3.7) we have

$$
\begin{aligned}
& \left\|x_{n+1}-x^{*}\right\| \leqslant\left[\left(1-\alpha_{n}\right)^{2}+2 \alpha_{n} k\right]\left\|x_{n}-x^{*}\right\|^{2}+2 \alpha_{n} e_{n}+2 M \cdot\left\|u_{n}\right\| \\
& \quad=\left[1-\alpha_{n}(1-k)+\alpha_{n}\left(\alpha_{n}-(1-k)\right)\right]\left\|x_{n}-x^{*}\right\|^{2}+2 \alpha_{n} e_{n}+2 M \cdot\left\|u_{n}\right\| .
\end{aligned}
$$

By conditon (ii), since $\alpha_{n} \rightarrow 0$ as $n \rightarrow \infty$, there exists a positive integer $n_{1}$ such that $\alpha_{n}-(1-k)<0$ for each $n \geqslant n_{1}$. Therefore we have

$$
\left\|x_{n+1}-x^{*}\right\|^{2} \leqslant\left(1-\alpha_{n}(1-k)\right)\left\|x_{n}-x^{*}\right\|^{2}+2 \alpha_{n} e_{n}+2 M\left\|u_{n}\right\|
$$

for all $n \geqslant n_{1}$. Apply Lemma 1.3 with $a_{n}=\left\|x_{n}-x^{*}\right\|^{2}, t_{n}=(1-k) \alpha_{n}, b_{n}=2 \alpha_{n} e_{n}$ and $c_{n}=2 M\left\|u_{n}\right\|$, and we have

$$
\left\|x_{n}-x^{*}\right\|^{2} \rightarrow 0 \text { as } n \rightarrow \infty \text {; that is, } x_{n} \rightarrow x^{*} \text { as } n \rightarrow \infty .
$$

Corollary 3.1. Let $X, D$ and $T$ be the same as in Theorem 3.1.

(1) For any $q \in F i x(T)$, we have $x^{*}=q$, and so $T$ has a unique fixed point in $D$;

(2) If $\left\{u_{n}\right\} \subset X$ and $\left\{\alpha_{n}\right\} \subset[0,1]$ are two sequences satisfying the following conditions:
(i) $\sum_{n=0}^{\infty}\left\|u_{n}\right\|<\infty$;
(ii) $\sum_{n=0}^{\infty} \alpha_{n}=\infty$ and $\alpha_{n} \rightarrow 0$ as $n \rightarrow \infty$, 
and if for some $x_{0} \in D$, the Mann iteration process with errors $\left\{x_{n}\right\}$ defined by

$$
x_{n+1}=\left(1-\alpha_{n}\right) x_{n}+\alpha_{n} \xi_{n}+u_{n}, \text { where } \xi_{n} \in T x_{n}
$$

belongs to $D$ and $T(D)$ is bounded in $X$, then

$$
x_{n} \rightarrow x^{*} \text { as } n \rightarrow \infty .
$$

Proof: Apply Theorem 3.1 with $\beta_{n}=0$ and $v_{n}=0$ for all $n \geqslant 0$. The conclusions follow immediately.

Theorem 3.2. Suppose $X$ is uniformly smooth, $D$ is a nonempty convex subset of $X$ and $T: D \rightarrow 2^{D}$ is a multivalued operator of monotone type such that $T x \neq \emptyset$ for all $x \in D$ and $F i x(T) \neq \emptyset$.

(1) If $q \in F i x(T)$, then $x^{*}=q$ where $x^{*}$ is the point appearing in (1.1).

(2) If, in addition, $T(D)$ is also bounded in $X$ and $\left\{\alpha_{n}\right\},\left\{\beta_{n}\right\}$ are two sequences in $[0,1]$ satisfying the following conditions:

(i) $\sum_{n=0}^{\infty} \alpha_{n}=\infty, \alpha_{n} \rightarrow 0$ as $n \rightarrow \infty$;

(ii) $\beta_{n} \rightarrow 0$ as $n \rightarrow \infty$.

Then for any $x_{0} \in D$, the Ishikawa iteration sequence $\left\{x_{n}\right\}$ defined by

$$
\begin{aligned}
x_{n+1} & =\left(1-\alpha_{n}\right) x_{n}+\alpha_{n} \eta_{n}, \text { where } \eta_{n} \in T y_{n} \\
y_{n} & =\left(1-\beta_{n}\right) x_{n}+\beta_{n} \xi_{n}, \text { where } \xi_{n} \in T x_{n}
\end{aligned}
$$

strongly converges to $x^{*}$.

Proof: Since $D$ is convex, for any $x_{0} \in D,\left\{x_{n}\right\},\left\{y_{n}\right\} \subset D$. Apply Theorem 3.1 with $u_{n}=v_{n}=0$ for all $n \geqslant 0$; the conclusions follow immediately.

REMARK. 1. Theorem 3.1, Corollary 3.1 and Theorem 3.2 improve and extend Dunn [6, Theorem 1], Chidume [2, Theorem 1] in several aspects.

2. Since every strictly pseudo-contractive mapping with a fixed point is a special case of monotone type mapping, Theorem 3.1 also improves and extends Liu [7, Theorem 2]. Moreover, Theorem 3.1, Corollary 3.1 and Theorem 3.2 also improve and extend the corresponding results of Chidume [3, Theorem 2]; [4, Theorem 4], Deng and Ding [5, Theorem 1], Tan and Xu [11, Theorem 3.2 and Theorem 4.2] and Chang [1, Theorem 3.3] in several aspects.

\section{REFERENCES}

[1] Shih-sen Chang, 'Some problems and results in the study of nonlinear analysis', Nonlinear Anal. 30 (1997), 4197-4208. 
[2] C.E. Chidume, 'Iterative construction of fixed points for multi-valued operators of the monotone type', Appl. Anal. 23 (1986), 209-218.

[3] C.E. Chidume, 'Approximation of fixed points of strongly pseudo-contractive mappings', Proc. Amer. Math. Soc. 120 (1994), 545-551.

[4] C.E. Chidume, 'Iterative solution of nonlinear equations with strongly accretive operators', J. Math. Anal. Appl. 192 (1995), 502-518.

[5] L. Deng and X.P. Ding, 'Iterative approximation of Lipschitz strictly pseudo-contractive mappings in uniformly smooth Banach spaces', Nonlinear Anal. 24 (1995), 981-987.

[6] J.C. Dunn, 'Iterative construction of fixed points for multi-valued operators of the monotone type', J. Funct. Anal. 27 (1978), 38-50.

[7] L.S. Liu, 'Ishikawa and Mann iterative process with errors for nonlinear strongly accretive mappings in Banach spaces', J. Math. Anal. Appl. 194 (1995), 114-125.

[8] M.O. Osilike, 'Stable iteration procedures for strong pseudo-contractions and nonlinear operator equations of the accretive type', J. Math. Anal. Appl. 204 (1996), 677-692.

[9] V.L. Smul'yan, 'Sur les topologies differentes dans l'espace de Banach', C.R. Acad. Sci. URSS 23 (1939), 331-334.

[10] V.L. Smul'yan, 'Sur la derivabilite de la norm dans l'espace de Banach', C.R. Acad. Sci. URSS 27 (1940), 255-258.

[11] K.K. Tan and H.K. Xu, 'Iterative solutions to nonlinear equations of strongly accretive operators in Banach spaces', J. Math. Anal. Appl. 178 (1993), 9-21.

Department of Mathematics

Sichuan University

Chengdu, Sichuan 610064

China
Department of Mathematics, Statistics and Computing Science

Dalhousie University

Halifax, Nova Scotia

Canada B3H 3J5 